https://helda.helsinki.fi

\title{
Is dental panoramic tomography appropriate for all young adults because of third molars?
}

\section{Vesala, Tommi}

2021-01-02

Vesala , T , Ekholm , M \& Ventä , I 2021 , ' Is dental panoramic tomography appropriate for all young adults because of third molars?' ', Acta Odontologica Scandinavica, vol. 79 , no. 1 , pp. 52-58 . https://doi.org/10.1080/00016357.2020.1776384

http://hdl.handle.net/10138/330899

https://doi.org/10.1080/00016357.2020.1776384

acceptedVersion

Downloaded from Helda, University of Helsinki institutional repository.

This is an electronic reprint of the original article.

This reprint may differ from the original in pagination and typographic detail.

Please cite the original version. 


\section{Is dental panoramic tomography appropriate for all young adults because of third molars?}

\section{Acta Odontologica Scandinavica}

Tommi Vesala ${ }^{\mathrm{a}}$, Marja Ekholm ${ }^{\mathrm{b}}$, Irja Ventä ${ }^{\mathrm{c}}$

${ }^{a}$ Department of Oral and Maxillofacial Diseases, University of Helsinki, Helsinki, Finland; ${ }^{b}$ Institute of Dentistry, University of Turku, Turku, Finland and South West Finland Imaging Centre, Turku University Hospital, Turku, Finland; ${ }^{c}$ Department of Oral and Maxillofacial Diseases, University of Helsinki, Helsinki, Finland

Address for correspondence: Tommi Vesala, Department of Oral and Maxillofacial Diseases, P.O. Box 41, FI-00014 University of Helsinki, Finland. Phone: +358505471413, Email: tommi.vesala@helsinki.fi

${ }^{\mathrm{a}} \mathrm{DDS} ;{ }^{\mathrm{b}} \mathrm{DDS}, \mathrm{PhD} ;{ }^{\mathrm{c}} \mathrm{DDS}, \mathrm{PhD}$

This is an Accepted Manuscript of an article published by Taylor \& Francis in Acta Odontologica Scandinavica on 2020 Jun 12, available online:

http://www.tandfonline.com/10.1080/00016357.2020.1776384 


\title{
Is dental panoramic tomography appropriate for all young adults because of third molars?
}

\begin{abstract}
Objective: The purpose of this study was to determine, if a dental panoramic tomograph (DPT) is appropriate for every young adult due to third molars.
\end{abstract}

Materials and Methods: The study sample consisted of 217 university students (20\% men and $80 \%$ women; mean age 20.7 years; $\mathrm{SD} \pm 0.6$ years) and included a questionnaire about symptoms caused by third molars, clinical oral examination of third molars, and a DPT. Subjects were divided into the following groups: subjects with a clinical indication for a DPT and subjects without such indication. The DPTs were then examined for findings regarding third molars.

Results: Clinical indication for a DPT was observed in 64\% of the subjects.

Radiography revealed an additional $1.4 \%$ of the subjects with $\geq 1$ radiographic signs of disease in relation to their third molars. Also, an additional $27 \%$ of the subjects had $\geq 1$ other radiographic findings in relation to third molars that may have affected the clinical decision making.

Conclusions: In our study population, clinically undetectable pathology cannot be considered as an indication for a DPT. However, if prevailing clinical practice supports preventive removals and detecting or monitoring of unerupted third molars, a referral to DPT can be considered as good clinical practice.

Keywords: Molar, third; Radiography, panoramic; Diagnosis, oral; Young adult 


\section{Introduction}

Third molars frequently cause symptoms, particularly in young adults. Accordingly, the majority of third molars are removed by the age of 40 years [1]. As symptoms and extractions of third molars are common, it is a matter of debate whether a radiological examination of all young adults should be performed systematically after clinical examination.

Based on the Cochrane review, it is unclear if asymptomatic and disease-free impacted wisdom teeth should be removed [2]. Thus, there are differences in recommendations of third molar treatment among countries. For example, in 2000, the National Institute of Clinical Excellence (NICE) introduced guidelines against prophylactic removal of third molars in the UK and listed specific clinical indications for surgery [3]. On the other hand, according to the Finnish Current Care Guidelines, in addition to the extraction of symptomatic third molars, preventive removals of asymptomatic teeth are also recommended in certain cases [4]. Also, according to a recent study, many of the organizational policy statements regarding third molar treatment in the US are in favor of prophylactic removals, while also a critical view is presented [5]. Thus, the differences in clinical practices affect the radiographic examination protocols of third molars.

The primary radiographic examination for third molars is dental panoramic tomography [6-8]. Although the radiation dose from a dental panoramic tomograph (DPT) is considered low $(0.02 \mathrm{mSv})$ [9], a radiographic examination must always be justified and the relevant risks and benefits for every patient should be considered. This is particularly important for children and young adults, as they are more susceptible than adults to the carcinogenic effects of ionizing radiation. Radiation exposure in young adults aged 20 to 30 years leads to a lifetime risk that is 1.5 times higher than in adults $>30$ years [6]. Effective doses of 14.2 to $24.3 \mu \mathrm{Sv}$ (corresponding to a risk of 0.8 to 1.3 fatal cancer cases per million people) from panoramic radiographs have been observed [9]. The benefits of the information 
obtained on third molars in a DPT should outweigh the potentially harmful effects of ionising radiation to the patient.

A recent study reported that no evidence exists to support screening with DPTs of all new adult patients [10]. Furthermore, a recent review of the current literature does not oppose the screening with DPTs at a national level, but the authors recommend further investigations for selection criteria and a quality management program of DPTs [11]. However, a specific analysis related to performing a DPT on every young adult due to third molars has not been presented. This study aimed to determine if a DPT is appropriate for every young adult even if the patient has no symptoms or clinical signs of disease in the third molars.

\section{Materials and methods}

Since screening radiography of subjects for research purposes is unacceptable, we utilized existing material from a previous study with questionnaires about symptoms, clinical oral examinations, and DPTs [12]. The material was gathered in 2002 at the Finnish Student Health Service (FSHS) in Helsinki when there was a routine to invite all first-year students to a free dental examination [12]. The data included a questionnaire about symptoms related to third molars, clinical oral examination including third molars, and DPTs. The subjects were all students that were born in Helsinki in 1981 to 1982 and studied at the University of Helsinki for their first year at the time of clinical and radiographic examinations. Students were from all faculties. In total, of the 277 invited students, $232(85 \%)$ participated voluntarily in a routine oral health examination [12]. The final sample consisted of 217 subjects; 15 DPTs were not available for examination as they had been sent to the patient or the private dentist. Although the subjects were not in a queue for extraction, after the examination they were given recommendations for all required dental treatment including those for third molars. In addition to age and gender, systemic diseases of the subjects were 
also recorded.

A questionnaire was used to inquire about the symptoms caused by third molars. The following choices were possible: 1) I have had no pain or symptoms, 2) my wisdom teeth have caused some pain or symptoms, but I haven't sought treatment, or 3) my wisdom teeth have caused pain or symptoms that have made me seek for treatment.

The third molars were examined clinically with respect to the state of eruption, state of occlusion, presence of dental caries or a filling, and pericoronitis (Table 1). The state of the eruption was examined visually and with a periodontal probe. The state of the eruption was recorded according to the size of the third molar crown that was visible in the mouth. The following were classified as clinical signs of disease: caries, filling (earlier caries), pericoronitis, over-eruption, and buccally inclined maxillary third molars.

Film-captured DPTs were obtained mainly with Planmeca Promax 2D (Helsinki, Finland) and some at the end of the study period with Soredex Cranex (Tuusula, Finland). All DPTs were examined by the first author with respect to the third molar findings. In uncertain cases, the senior authors in oral and maxillofacial surgery and oral radiology were consulted. Examination of DPTs was performed at facilities of the FSHS on a viewing screen and SDI $\mathrm{X}$-ray reader in dimmed room lighting.

Radiographs were examined for maxillary and mandibular third molars (Table 2). Every third molar was recorded separately; several different recordings per subject were thus possible. Signs of disease were recorded separately for each subcategory per subject and subjects with $\geq 1$ signs of disease were recorded. The marginal bone level on the distal surface of the mandibular second molar, next to the mandibular third molar, was recorded according to the most severe finding per subject. The state of the eruption was recorded as unerupted if the tooth was clinically unerupted but visible in DPT. 
After 100 DPTs had been evaluated, the first 10 DPTs were re-evaluated for harmonization of recordings. After examination of all DPTs, 20 (9\%) DPTs were randomly selected and re-evaluated to assess the intra-examiner reliability of the measurements.

Data were analyzed considering the subject as an observation unit. Subjects were divided into the following two groups: subjects with a clinical indication for a DPT and subjects without such clinical indication. Clinical indication for a DPT included general health issues, symptoms with third molars, partial eruption of at least one third molar, or clinically recorded signs of disease in relation to at least one third molar. Radiographic findings of third molars were analyzed from all subjects and reported also separately for the subjects without clinical indication for a DPT. Finally, clinical and radiographic findings were combined and DPT's possible effect on clinical decision making for a subject was determined. Descriptive analyses were performed with the Excel (Microsoft, Washington, USA) spreadsheet program. Kappa values were computed with IBM SPSS Statistics version 24 (IBM Corp., Armonk, NY, USA).

The institutional review board at the FSHS approved the clinical and radiographic examinations at baseline. Permission to use the existing material for the present study was obtained from the FSHS headquarters.

\section{Results}

The study sample consisted of 217 subjects ( $20 \%$ men, $80 \%$ women). The mean age was 20.7 years ( $\mathrm{SD} \pm 0.6$ years). Regarding intra-examiner reliability of the measurements, the agreement was $97 \%$ for the developmental stage of the root end, $97 \%$ for marginal bone level on the distal surface of the mandibular second molar, and $100 \%$ for other variables. Kappa values were 0.94 for the developmental stage of the root end, 0.95 for marginal bone level, and 1.00 for other measurements. Kappa values between 0.81 and 1.00 were considered very good. 
At least one clinical indication for a DPT was observed in 139 (64\%) subjects (Figure 1). General health indications included diabetes in 2 subjects. According to the questionnaire, $132(61 \%)$ subjects reported no symptoms, 51 (24\%) subjects have had some pain or symptoms but had not sought treatment, and 34 (16\%) subjects have had pain or symptoms which have made them seek treatment. Clinical signs of disease in at least one third molar included caries, restoration, or both in $23(11 \%)$ subjects, over-eruption in $23(11 \%)$, pericoronitis in $10(5 \%)$, and buccally inclined maxillary third molar in $20(9 \%)$ subjects. Several signs of disease per subject were possible.

In the radiographic analysis of all subjects, at least one radiographic finding in relation to at least one third molar was found in 189 (87\%) subjects (Figure 2). Signs of disease were recorded in $49(23 \%)$ subjects. No apical periodontitis or root resorption was found. Marginal bone level consisted of subjects with the most severe recording per subject being at the cervical third of the root in $63(29 \%)$ subjects, at the middle third of the root in $30(14 \%)$, and at the apical third of the root in $1(0.5 \%)$ subject. A close relationship between the roots of the mandibular third molar and the inferior alveolar canal (IAC) consisted of subjects with at least one of the following findings in at least one mandibular third molar: interruption of the white line of the IAC cortex in $167(77 \%)$ subjects, darkening of the mandibular third molar root in $58(27 \%)$, bending of the IAC next to the third molar root in $10(5 \%)$, and the apex of a mandibular third molar located inferior to IAC in 21 (10\%) subjects.

When the DPTs of the 78 subjects (36\% of all) with no clinical indication for radiography were analyzed separately, it was found that $62(79 \%)$ of these subjects had at least one radiographic finding in at least one third molar (Figure 3). Signs of disease were recorded in $3(4 \%)$ subjects. Marginal bone level consisted of subjects with the most severe recording per subject being at the cervical third of the root in $22(28 \%)$ subjects, at the middle third of the root in $20(26 \%)$, and at the apical third of the root in $1(1 \%)$ subject. Close 
relationship with the IAC consisted of subjects with interruption of the white line in $59(76 \%)$ subjects, darkening of the root in $14(18 \%)$, bending of IAC in $5(6 \%)$, and inferior to IAC in $8(10 \%)$ subjects. Concerning the development of the root, $42(54 \%)$ subjects had at least one third molar with an incomplete apex in close relationship with the IAC.

Finally, when considering all the recordings of general health, symptoms, and clinical and radiographic findings of all subjects together, clinical indication for a DPT was observed in $139(64 \%)$ subjects. In addition to these subjects, radiographic signs of disease were observed in $3(1.4 \%)$ subjects and $59(27 \%)$ subjects had other radiographic findings in relation to third molars, such as a difference in marginal bone level, third molar and IAC closely related, or supernumerary tooth in the third molar region (Figure 4). The remaining 16 (7\%) subjects had no clinical indication for radiography or relevant radiographic findings in third molars. Of these remaining 16 subjects, 1 subject had all mandibular and maxillary third molars that were erupted, 9 subjects had only unerupted maxillary third molars, and 6 subjects did not have any third molars. Of these 16 subjects, 5 were men and 11 were women.

\section{Discussion}

The main result of our study was that among the 21 -year-old adults, in addition to the $64 \%$ of subjects with a clinical indication for a DPT, only $1.4 \%$ had signs of disease in their third molars that were disclosed from a DPT. However, an additional $27 \%$ of the subjects had other radiographic findings in relation to third molars. The relevance of these findings, and thus the relevance of the DPT, depends on the policy of third molar treatment, which varies among countries. This finding is important and suggests that DPT of all young adults cannot be supported nor opposed unambiguously but should be weighed against the prevailing clinical practice in each country. 
To our knowledge, this may be the first published study that considers the acceptability of taking a DPT due to third molars in young adults. Similar studies are therefore not available for comparison to assess the significance of our results. Unlike in many other studies, our study sample consisted of university students that participated voluntarily in a routine oral health examination and were not referred to surgical treatment prior to examination. For example, in a US study on 249 patients at a surgical unit, a high occurrence of subjects ( $88 \%)$ either with symptoms or clinical or radiographic signs of disease in relation to third molars was reported [15]. Recommendations for radiographic imaging has also been made in the US: American Academy of Pediatric Dentistry recommends radiographic examination in late adolescence to assess the presence, position, and development of third molars [16]. Radiographic examination is also recommended as part of active surveillance of retained mandibular third molars every 2 years [17], even though there are no randomized controlled trials to support this recommendation.

The use of DPT as an overall screening procedure has been questioned in several studies [10,18-20]. The additional diagnostic value of DPT is reported to be low or insufficient to support screening, or the majority of screening DPTs had no relevance to treatment $[10,18-20]$. On the other hand, in a Korean study, a DPT was reported to be valuable in the overall assessment of dentition from a diagnostic point of view [11]. However, the populations in these studies consisted mostly of age groups other than young adults and specific analyses for third molars were not performed.

Regarding radiographic signs of disease, the prevalence of caries and pericoronal radiolucency can be assessed from studies where DPTs of subjects scheduled for third molar removal are analyzed. In such studies, caries in examined third molars was observed at a prevalence between $5.3 \%$ and $13.6 \%$, and pericoronal radiolucency in mandibular third molars at a prevalence between $6.3 \%$ and $14.7 \%$ [21-23]. These numbers are compatible with 
our $6 \%$ of caries and $7 \%$ of pericoronal radiolucency observed in all subjects, but much higher than the $1 \%$ of caries and $1 \%$ of pericoronal radiolucency observed in our subjects without clinical indication for radiography. In our study, the DPT disclosed only a few additional signs of disease in subjects with no clinical indication for a DPT. Thus, clinically undetectable pathology cannot be considered as an indication for DPT in this study population.

Regarding other radiographic findings in the third molars, the clinical relevance of them has to be considered. The relevance is mostly based on the assessment of preventive extractions, monitoring of unerupted third molars, and patient informing. The differences in clinical practices of third molar treatment among countries affect the generalizability of our results.

Slightly more than half of our subjects with no clinical indication for radiography had a difference in marginal bone level on the distal surface of at least one mandibular second molar. Similar to our results, a Danish study of third molars with cone-beam computed tomography revealed reduced alveolar bone heights in almost half of the examined mandibular second molars [24]. Contrary to our findings, a radiographic study from Turkey reported periodontal damage on an adjacent tooth at a prevalence of only $8.9 \%$ [22]. Part of the marginal bone levels in our study may have changed later on due to the continuing eruption of the third molars $[25,26]$. However, a US study suggests that eruption to occlusal level does not necessarily improve the periodontal status in the third molar region [27]. Also, impacted third molars are at greater risk to develop periodontal pathology with continuing retention over a long time [28]. It remains uncertain, whether differences in marginal bone levels in our study were only a temporary consequence of eruption, or a sign of increased risk for a third molar associated periodontal pathology. 
The close relationship between the mandibular third molar and the IAC is a wellknown predisposing factor for nerve injury in mandibular third molar surgery [29]. In a Chinese study, the possibility for early extractions of third molars with incomplete root development is included to prevent postoperative complications, especially nerve injury [30]. Of our subjects with no clinical indication for radiography, over a half had at least one mandibular third molar with one or several signs of a close relationship with the IAC and an incomplete root end. However, it should be noted that when a three-dimensional image is taken after a routine radiograph, the number of teeth with a close relationship with the IAC decreases by $60 \%$ [31]. If preventive extractions due to the close relationship with the mandibular third molar and the IAC are considered good clinical practice, a DPT would be necessary.

The mean age in our study (20.7 years) is noteworthy because third molars undergo continuous positional changes through young adulthood $[25,26]$. The number of erupted and partially erupted third molars, clinical signs of disease, and radiographic signs of disease would probably have increased in the following years [27,32]. Also, increased age (over 25 years) appears to be associated with a higher complication rate for third molar extractions [33], which supports the early assessment of third molar treatment.

The development of DPT imaging is far advanced, and it is also possible to obtain a partial DPT. In a recent UK study, full-width DPT was not required in most instances, and segmental DPT was advised to be regarded on a more regular basis [34]. The segments required were most often the molar and premolar regions bilaterally, the same segments that include third molars. Advanced imaging modalities, such as segmental DPT, could prove beneficial in minimizing the effective dose of ionizing radiation and risk for stochastic effects. 
A limitation of our study is that clinical data of probing depths distal to second molars and around third molars were lacking. Clinical probing depths combined with data from DPTs could have given more specific knowledge of the current periodontal status of third molars. Also, because the questions about symptoms were general, the correlation between symptoms and specific radiographic findings cannot be concluded. Furthermore, our subjects were university students born and living in the capital of the country. It may be that their state of oral health was better than in the general population of the same age. A strength of the study is that the subjects were not from a surgical unit waiting for third molar surgery. The subjects were also of the same age, as the SD was only 0.6 years.

It is concluded that a DPT is appropriate only if it presents further substantial information that has an impact on patient diagnosis, treatment, or a comprehensive treatment plan. Since the DPTs disclosed only a few additional signs of disease, clinically undetectable pathology cannot be considered as an indication for a DPT in our study population. If the emphasis is put on preventive removals, detecting and monitoring of unerupted third molars, and informing the patient of the current status and treatment options for third molars, a DPT of young adults can be considered as good clinical practice.

Acknowledgements: We thank the FSHS and Lauri Turtola, DDS, PhD, former Chief Dental Officer at the FSHS, for organization of the field investigation.

Disclosure of interest: The authors report no conflict of interests.

Source of funding: The field survey was organized and funded by the Finnish Student Health Service, Helsinki, Finland. 
References

[1] Kautto A, Vehkalahti MM, Ventä I. Age of patient at the extraction of the third molar. Int J Oral Maxillofac Surg. 2018;47(7):947-951.

[2] Ghaeminia H, Perry J, Nienhuijs ME, et al. Surgical removal versus retention for the management of asymptomatic disease-free impacted wisdom teeth. Cochrane Database Syst Rev. 2016;8:CD003879.

[3] National Institute for Clinical Excellence. Guidance on the extraction of wisdom teeth [Internet]. London: NICE. [published 2000 Mar 27; cited 2020 May 7]. Available from: https://www.nice.org.uk/guidance/ta1

[4] Third Molar [Internet]. Helsinki: Current Care Guidelines. Working group set up by the Finnish Medical Society Duodecim and the Finnish Dental Society Apollonia. The Finnish Medical Society Duodecim [published 2020 Mar 12; cited 2020 May 7]. Available from: https://www.kaypahoito.fi/hoi50074

[5] Rafetto LK. Managing impacted third molars. Oral Maxillofac Surg Clin North Am. 2015;27(3):363-371.

[6] European Commission. Radiation Protection 136 [Internet]. Luxembourg: European guidelines on radiation protection in dental radiology. The safe use of radiographs in dental practice. EC report 136 [published 2004; cited 2020 May 7]. Available from: https://ec.europa.eu/energy/sites/ener/files/documents/136.pdf

[7] Flygare L, Ohman A. Preoperative imaging procedures for lower wisdom teeth removal. Clin Oral Investig. 2008;12(4):291-302.

[8] Meara DJ. Evaluation of third molars: clinical examination and imaging techniques. Atlas Oral Maxillofac Surg Clin North Am. 2012;20(2):163-168.

[9] Ludlow JB, Davies-Ludlow LE, White SC. Patient risk related to common dental radiographic examinations: the impact of 2007 International Commission on 
Radiological Protection recommendations regarding dose calculation. J Am Dent Assoc. 2008;139(9):1237-1243.

[10] Rushton MN, Rushton VE. A study to determine the added value of 740 screening panoramic radiographs compared to intraoral radiography in the management of adult (>18 years) dentate patients in a primary care setting. J Dent. 2012;40(8):661-669.

[11] Choi JW. Assessment of panoramic radiography as a national oral examination tool: review of the literature. Imaging Sci Dent. 2011;41(1):1-6.

[12] Ventä I, Turtola L. Korkeakouluopiskelijoiden suun terveyden muutokset kolmen ensimmäisen opiskeluvuoden aikana [Changes in the oral health of university students during the first three years of studies]. Helsinki, Finland: Ylioppilaiden terveydenhoitosäätiön tutkimuksia 44; 2008 [cited 2020 May 7]; [1-104]. Finnish. Available from: https://docplayer.fi/4051888-Korkeakouluopiskelijoiden-suunterveyden-muutokset-kolmen-ensimmaisen-opiskeluvuoden-aikana.html

[13] Rood JP, Shehab BA. The radiological prediction of inferior alveolar nerve injury during third molar surgery. Br J Oral Maxillofac Surg. 1990;28(1):20-25.

[14] Haavikko K. The formation and the alveolar and clinical eruption of the permanent teeth. An orthopantomographic study. Suom Hammaslaak Toim. 1970;66(3):103-170.

[15] Kinard BE, Dodson TB. Most patients with asymptomatic, disease-free third molars elect extraction over retention as their preferred treatment. J Oral Maxillofac Surg. 2010;68(12):2935-2942.

[16] American Academy of Pediatric Dentistry. Guideline on management considerations for pediatric oral surgery and oral pathology. Pediatr Dent. 2016;38(6):315-324.

[17] Dodson TB. Surveillance as a management strategy for retained third molars: Is it desirable? J Oral Maxillofac Surg. 2012;70(9 Suppl 1):S20-S24. 
[18] Barrett AP, Waters BE, Griffiths CJ. A critical evaluation of panoramic radiography as a screening procedure in dental practice. Oral Surg Oral Med Oral Pathol. 1984;57(6):673-677.

[19] Rushton VE, Horner K, Worthington HV. Screening panoramic radiology of adults in general dental practice: radiological findings. Br Dent J. 2001;190(9):495-501.

[20] Martínez Beneyto Y, Alcráz Banos M, Pérez Lajarin L, et al. Clinical justification of dental radiology in adult patients: a review of the literature. Med Oral Patol Oral Cir Bucal. 2007;12(3):E244-E251.

[21] van der Linden W, Cleaton-Jones P, Lownie M. Diseases and lesions associated with third molars. Review of 1001 cases. Oral Surg Oral Med Oral Pathol Oral Radiol Endod. 1995;79(2):142-145.

[22] Polat HB, Özan F, Kara İ, et al. Prevalence of commonly found pathoses associated with mandibular impacted third molars based on panoramic radiographs in Turkish population. Oral Surg Oral Med Oral Pathol Oral Radiol Endod. 2008;105(6):e41e47.

[23] Al-Khateeb TH, Bataineh AB. Pathology associated with impacted mandibular third molars in a group of Jordanians. J Oral Maxillofac Surg. 2006;64(11):1598-1602.

[24] Matzen LH, Schropp L, Spin-Neto R, et al. Use of cone beam computed tomography to assess significant imaging findings related to mandibular third molar impaction. Oral Surg Oral Med Oral Pathol Oral Radiol. 2017;124(5):506-516.

[25] Ventä I, Turtola L, Ylipaavalniemi P. Change in clinical status of third molars in adults during 12 years of observation. J Oral Maxillofac Surg. 1999;57(4):386-389.

[26] Kruger E, Thomson WM, Konthasinghe P. Third molar outcomes from age 18 to 26: Findings from a population-based New Zealand longitudinal study. Oral Surg Oral Med Oral Pathol Oral Radiol Endod. 2001;92(2):150-155. 
[27] Ahmad N, Gelesko S, Shugars D, et al. Caries experience and periodontal pathology in erupting third molars. J Oral Maxillofac Surg. 2008;66(5):948-953.

[28] Nunn ME, Fish MD, Garcia RI, et al. Retained asymptomatic third molars and risk for second molar pathology. J Dent Res. 2013;92(12):1095-1099.

[29] Tay ABG. Effect of exposed inferior alveolar neurovascular bundle during surgical removal of impacted lower third molars. J Oral Maxillofac Surg. 2004;62(5):592-600.

[30] Zhang QB, Zhang ZQ. Early extraction: a silver bullet to avoid nerve injury in lower third molar removal? Int J Oral Maxillofac Surg. 2012;41(10):1280-1283.

[31] Nakamori K, Fujiwara K, Miyazaki A, et al. Clinical assessment of the relationship between the third molar and the inferior alveolar canal using panoramic images and computed tomography. J Oral Maxillofac Surg. 2008;66(11):2308-2313.

[32] Ventä I, Vehkalahti MM, Huumonen S, Suominen AL. Signs of disease occur in the majority of third molars in an adult population. Int J Oral Maxillofac Surg. 2017;46(12):1635-1640.

[33] Chuang SK, Perrott DH, Susarla SM, et al. Age as a risk factor for third molar surgery complications. J Oral Maxillofac Surg. 2007;65(9):1685-1692.

[34] Bell GW, Donaldson KJ, Walton RL, et al. Justification of full width panoramic radiography in oral surgery. Oral Surg. 2016;10(2):86-92. 
Table 1. Clinical measurements of all third molars.

\begin{tabular}{lll}
\hline Measurement & Category & Definition \\
\hline State of eruption & Missing & Missing or unerupted \\
& Partially erupted & Detectable with a probe from the distal \\
& surface of the second molar \\
& Part of the occlusal surface clinically \\
& visible \\
& Occlusal surface fully visible \\
& Crown partially visible \\
& Crupted & Crown fully visible
\end{tabular}

State of occlusion Above occlusal plane

At occlusal plane

Below occlusal plane

Maxillary third molar erupting buccally

Caries Intact

Restoration

Dentinal caries

Pericoronitis Yes

No 
Table 2. Radiographic measurements of the third molars.

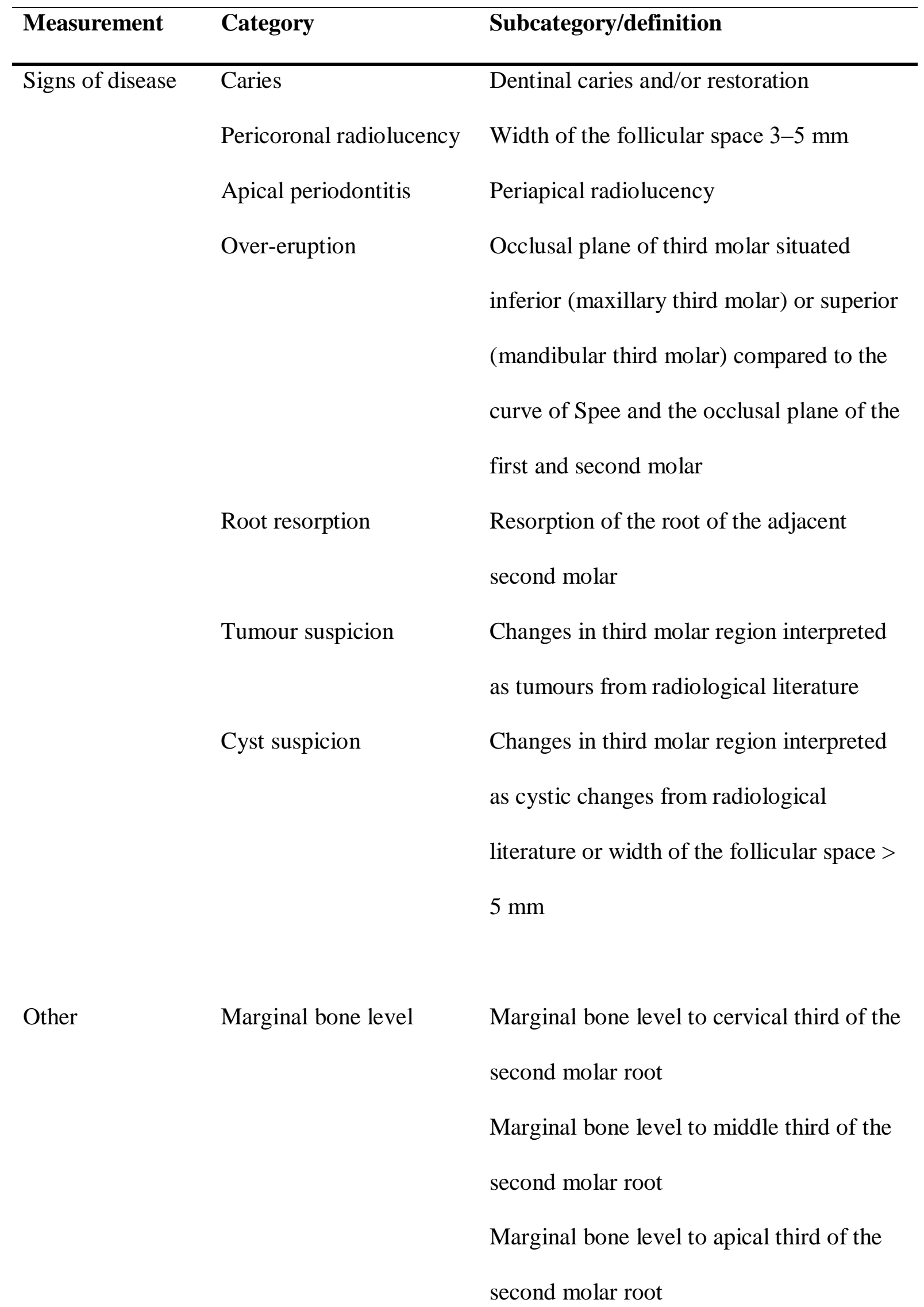


Close relationship with Bending of IAC next to apex of the third the inferior alveolar canal molar root (IAC) and the roots of Darkening of the third molar root the third molar [13] Interruption of the white line of the IAC cortex

Root of the third molar extending inferior to IAC

Developmental stage of Incomplete: Apices of the roots not closed the root end [14] Finished: Apices of the roots closed 
Figure 1. Distribution (\%) of clinical indications for a DPT among the 217 subjects. Several indications per subject were possible.

Figure 2. Distribution (\%) of radiographic findings of third molars in all 217 subjects. Several findings per subject were possible.

Figure 3. Distribution (\%) of radiographic findings in the 78 subjects with no clinical indication for radiography. Several findings per subject were possible.

Figure 4. Combination (\%) of clinical indications for a DPT, signs of disease in radiography, and other radiographic findings in relation to third molars in all 217 subjects. Several findings per subject were possible. 


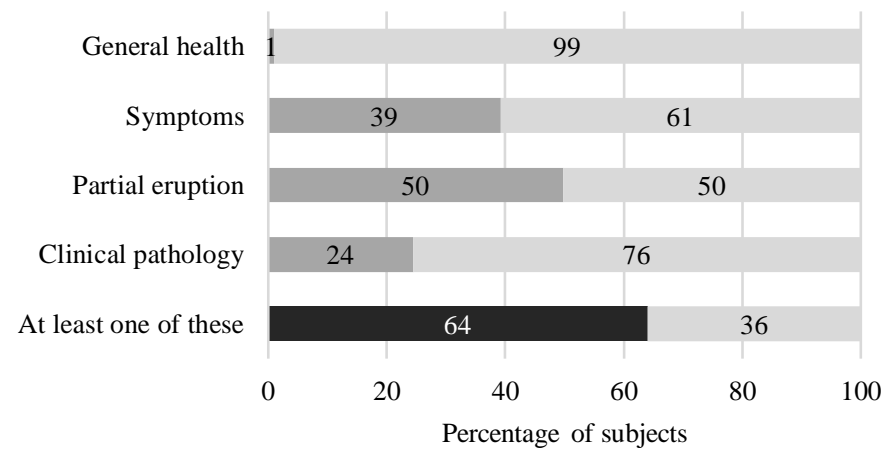

With indication Without indication $\quad$ All findings combined

Figure 1. 


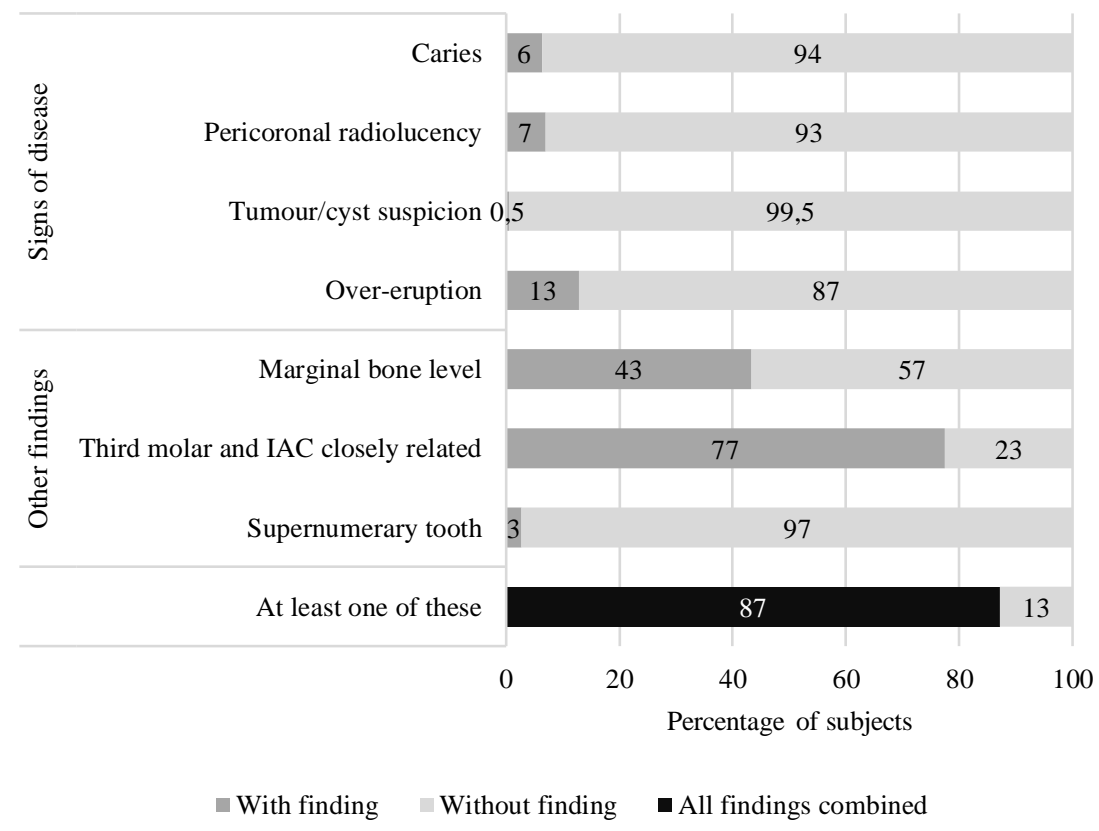

Figure 2. 


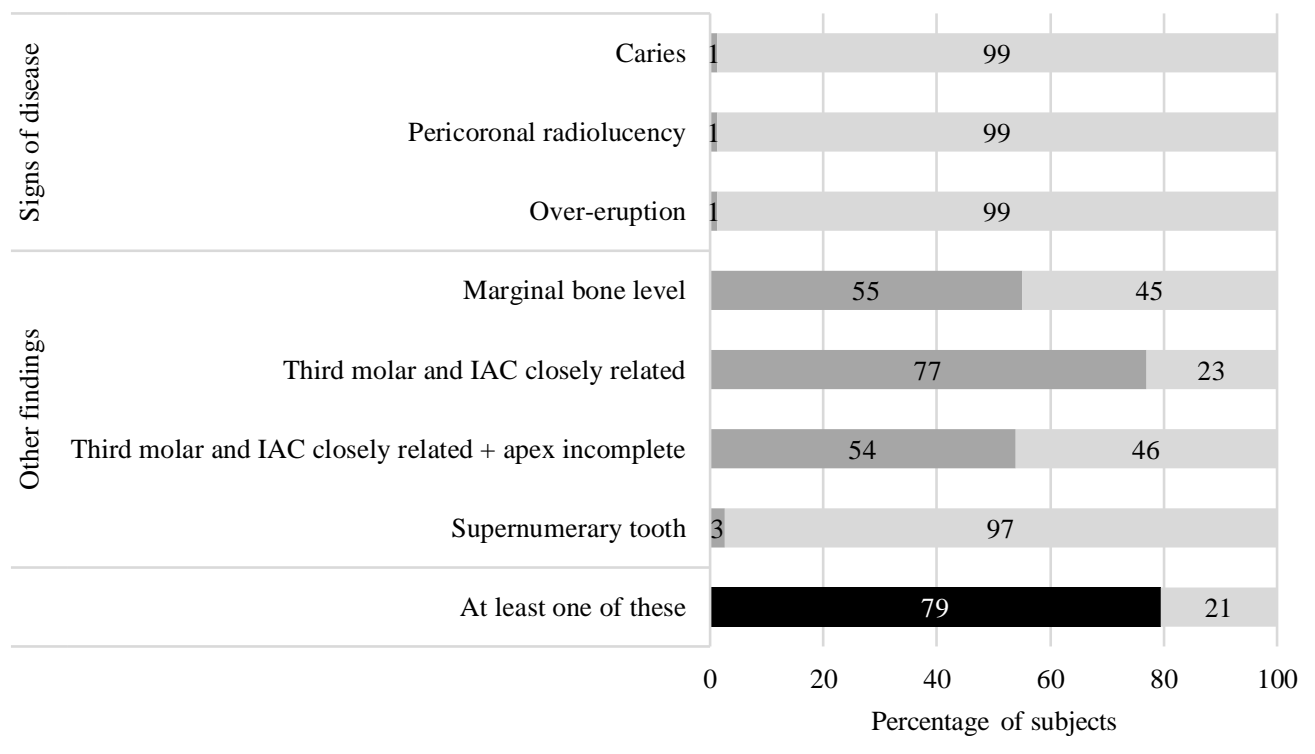

With finding Without finding $\quad$ All findings combined

Figure 3. 


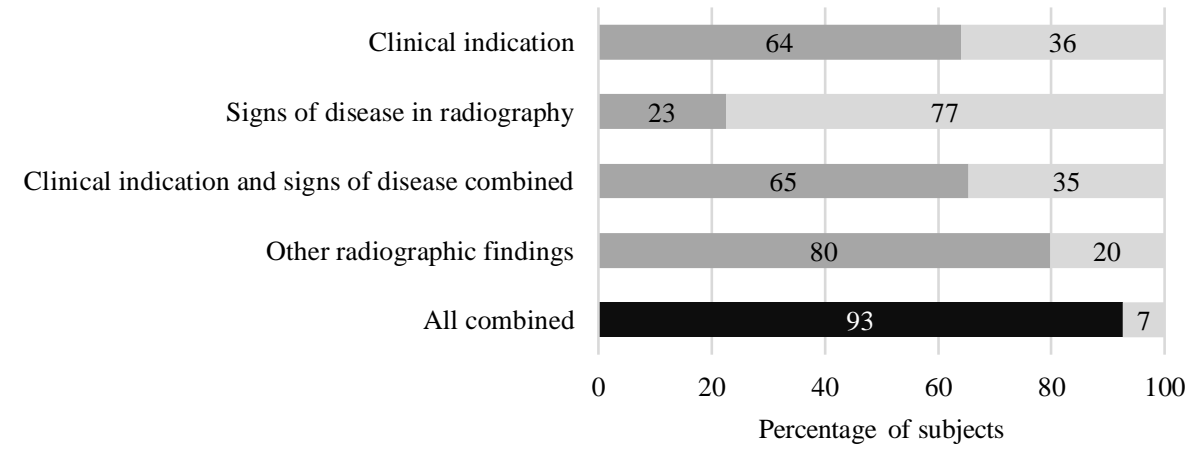

-With finding $\square$ Without finding $\quad$ All combined

Figure 4. 